УДК 81 '23

DOI: $10.17223 / 19986645 / 45 / 6$

\title{
Ж.Б. Жалсанова
}

\section{ОБРАЗ «ДАРХАНА / КУЗНЕЦА» В БУРЯТСКОЙ КУЛЬТУРЕ (ПСИХОЛИНГВИСТИЧЕСКОЕ ЗНАЧЕНИЕ)}

\begin{abstract}
Статья посвящена анализу образа «дархана / кузнеиа» в языковом сознании представителей бурятской культуры. В работе рассмотрены психолингвистическое и лексикографическое значения слова «дархан», выявлено функиионирование его словарных значений. На основе проведенного анализа языковых образов носителей билингвов со знанием бурятского и русского языков и бурят с родным русским языком выявлены общие черты и специфика культа кузнеиа в условиях бурятско-русского двуязычия в Республике Бурятия.

Ключевые слова: этнопсихолингвистика, языковое сознание, свободный ассоииативный эксперимент, психолингвистическое значение, лексикографическое значение, образ дархана / кузнеца.
\end{abstract}

Этнопсихолингвистика - одно из направлений в психолингвистике, которое изучает национально-культурную специфику языкового сознания. Под языковым сознанием мы вслед за Е.Ф. Тарасовым подразумеваем совокупность структур сознания, в формировании которых были использованы социальные знания, связанные с языковыми знаками, а также образы сознания, овнешняемые языковыми средствами, отдельными лексемами, словосочетаниями, фразеологизмами, текстами, ассоциативными полями и ассоциативными тезаурусами как совокупностью этих полей. Образы языкового сознания интегрируют в себе языковые знания, формируемые самим субъектом, преимущественно в ходе речевого общения, и чувственные знания, возникающие в сознании в результате переработки перцептивных данных, полученных от органов чувств в предметной деятельности [1. С. 9]. Сознание человека наполнено образами, в каждой культуре имеющими неповторимые особенности, собственный характер и состоящими в определенных отношениях с другими образами. Через их систему складывается канон восприятия реальности - комплекс культурных репрезентаций.

Один из методов исследования языкового сознания - ассоциативный эксперимент [2. С. 130] - дает возможность выявить системность содержания образа сознания, стоящего за словом в той или иной культуре, и системность языкового сознания носителей культуры как целого, т.е. его этнокультурную специфику. Получаемое в результате проведения такого эксперимента ассоциативное поле слова-стимула - это не только фрагмент вербальной памяти человека, но и фрагмент образа мира этноса, отраженного в сознании «среднего» носителя культуры, его мотивов и оценок и, следовательно, его культурных стереотипов [3. С. 261-263].

Материалом для исследования служат данные бурятского ассоциативного словаря [4] и толковых словарей бурятского языка $[5,6]$. Бурятский ассоциа- 
тивный словарь был составлен в ходе свободного ассоциативного эксперимента с регистрацией первого ответа. Цель эксперимента заключалась в выявлении этнической составляющей гендерных стереотипов в бурятской и русской культурах. Испытуемым был предъявлен список стимулов, раскрывающих стереотипы МУЖЕСТВЕННОСТЬ (мужчина / эрэ хүн, отец / эсэгэ, муж / үбгэниинь, глава семьи / гэр бүлын толгой, хозяин / эзэн, защитник / хамгаалагша, охотник / ангуушан, кузнец / дархан, дедушка / үбгэн баабай, брат / аха, дүү хүбүүн, мальчик, парень, сын / хүбүүн) и ЖЕНСТВЕННОСТЬ (женщина / эхэнэр, жена / һамган, мать / эхэ, хозяйка / эзэн эхэнэр, хранительница очага / гал гуламтын эзэн, красавица / дангина, подруга / хани басаган, бабушка / хүгшэн эжы, девочка / жаахан басаган, девушка, дочь / басаган, сестра / эгэшэ, дүү басаган, теща / хадам эхэ), с просьбой зафиксировать ассоциации на родном языке, возникающие в связи со стимулом.

Эксперимент был проведен в г. Улан-Удэ (Республика Бурятия) в следующих учебных заведениях: Бурятский государственный университет, Восточно-Сибирский государственный технологический университет, ВосточноСибирская государственная академия культуры и искусств, Бурятская государственная сельскохозяйственная академия, Бурятский республиканский педагогический колледж, музыкальный колледж им. П.И.Чайковского. В эксперименте приняли участие 600 человек (студенты в возрасте 17-25 лет) 3 группы испытуемых по 200 человек - 100 мужчин и 100 женщин:

- буряты, для которых бурятский язык является родным, русский язык вторым, в эксперименте они обозначены как «буряты 1, б1»;

- буряты, считающие русский язык родным языком и не владеющие бурятским языком, - «буряты 2, б2»;

- русские, проживающие в Республике Бурятия, - «русские, p».

В целом в эксперименте было получено и проанализировано 15400 реакций: буряты $1-5000$, буряты $2-5200$, русские -5200 , количество отказов составило 260.

В данной статье мы попытаемся выявить «психолингвистическое значение слова» (термин И.А. Стернина, А.В. Рудаковой) «ДАРХАН / КУЗНЕЦ» в бурятской культуре. Психолингвистическое значение слова определяется как упорядоченное единство всех семантических компонентов, которое актуализирует изолированно взятое слово в сознании носителей языка, это реально функционирующее в языковом сознании носителей языка значение слова [7. С. 176]. Как считают И.А. Стернин и А.В. Рудакова, психолингвистическое значение слова шире, чем лексикографическое, зафиксированное в толковых словарях. Инструментом для выявления психолингвистического значения слова может выступать свободный ассоциативный эксперимент, на основе которого составляются ассоциативные словари.

В настоящее время в Республике Бурятия наблюдается ситуация бурятско-русского двуязычия не в пользу бурятского языка [8. С. 191]. Несмотря на усилия СМИ и национальной школы, в бурятском языке наблюдается интерференция со стороны русского языка, бурятский язык уступает русскому как основному языку общения в республике. Культ кузнеца в бурятской культуре издавна связан с религией, интересным представляется выявить, 
каков этот реальный образ в языковом сознании носителей культуры в условиях доминирования русского языка. НЕЦ.

Рассмотрим ассоциативные реакции бурят на стимул ДАРХАН / КУЗ-

\section{Буряты 1 (б1) ДАРХАН}

уран 32, хүн 16, түмэр 12, бэрхэ 11, шадалтай 10, модон 9, алтан гартай, дархална,6, бөө, гартаа уран, эрэ 5, аба, алтан, баабай, найн 4, барилгама, модошон, түмэр, үбгэн 3, абга, ажал, ажалман, алха, дархашан, дащан, сохино, столяр, таабай, хүбүүн, хүшэтэй 2, абаха, абгай, алтан гар, барилга, баряаша, болохо, бригада, бурхан, бэлигтэй, гар гүй, гэр, гэр баряама, зураха, зурааман, зүҮдхэлнүҮд, ном, подкова, стол, табиба, талан, ҮҮдэн, хадааһан, хара, харуул, хоршогор, хүдэлмэришэн, хүдэлнэ, шулуун, шэнэ гэр, эдеэн 1; $200+60+3+30$ (Первая цифра указывает общее число реакций на слово-стимул, вторая - число разных реакций, третья - число отказов испытуемых, четвертая - число единичных реакций, т.е. число ответов с частотой 1.)

\section{Буряты 2 (б2) КУЗНЕЦ}

молот 26, подкова 22, железо 14, металл 12, счастья 11, кузница, счастье 7, мастер, работа, работник, труд, украшение 6, металл, меч 5, дархан 4, наковальня, рабочий, сильный, своего счастья, сила, сталь 3, ковать, ковка, огонь, молоток, ремесло, ремесленник, умельй, шаман 2, Вася, горячий, женщина, закаленный, искусный, ковка мечей, клещи, ковальня, корова, красное железо, красный, кувалда, кует, лошадь, мельница, мечник, молоток, олово, он, оружсие, очень нужный, песня «КИШ», «Пираты Карибского моря», работяга, рабочий, седло, специальность, старый, талантливый, твореи, топор, трава, тяжесть, Фома; $200+63+0+34$

Русские (p) КУЗНЕЦ

молот 25, подкова 24, железо 22, счастье 13 , кует 10, счастья 8, работа 6, металл, наковальня, сила, труд 5, кует, ковать, сильныий 4, кузница, мастер, меч, огонь 3, Вакула, Гефест, золотые руки, ковка, молодеи, молот, молоток, мужсик, мужчина, оружие, профессия, работник, рабочий, ремесло, хороший 2, балбес, богатырь, Вуттон, в кузниче, в поле, давно, дичь, железный, здоровый мужик, изделие, искусство, ковка, копыто, купеи, лошадь, месть, мощь, ножницы, работяга, своего счастья, силач, спеииальность, сталь, старый, твореи, трудяга, умельй 1;200+60+1+27

Для анализа ассоциативных реакций мы используем классификацию «семантический гештальт» Ю.Н. Караулова, которая отражает внутреннюю семантического организацию ассоциативного поля и характеризует поле как полную единицу знания о мире. Описывая важнейшее отношение «язык действительность», «семантический гештальт» базируется на причастности каждой реакции к тому или другому стереотипному свойству данного референта в данном языке и выстраивается путем естественной семантической классификации входящих в поле ассоциатов. Семантический гештальт складывается обычно из нескольких зон (их число колеблется в пределах $7 \pm 2$ ), которые объединяют типичные для данного языкового сознания признаки 
предмета или понятия, соответствующего имени поля (т.е. стимулу) [9. C. 220].

1. Персоналии - слова-реакции, обозначающие персоналии, лица, ассоциируемые со словом-стимулом.

2. Реалии - слова-реакции, обозначающие предметы, конкретные и абстрактные понятия, животных, ассоциируемые со словом стимулом.

3. Признаки - слова-реакции, обозначающие постоянные (интегральные) признаки: физиологические характеристики, физические данные, внешность.

4. Оценки - слова-реакции, обозначающие оценочные характеристики (дифференциальные признаки): черты характера, характеристики умственных способностей.

5. Эмоции - слова-реакции, обозначающие эмоциональные состояния и чувства.

6. Количество - слова-реакции, обозначающие количество.

7. Место - слова-реакции, обозначающие местонахождение.

8. Время - слова-реакции, обозначающие время.

9. Деятельность - слова-реакции, обозначающие деятельность, процесс, действия, ассоциируемые со словом-стимулом.

10. Отказ.

На основе данной классификации были проведены следующие процедуры:

- распределение реакций по семантическим зонам в ассоциативном поле;

- подсчет количества реакций в каждой зоне для выявления приоритетных семантических зон;

- описание и интерпретация содержания образов сознания в русской и бурятской культурах;

- выявление сходства и установление образов в языковом сознании русских и бурят.

Согласно классификации ассоциаций «семантический гештальт» реакции распределились следующим образом (рис. 1).

Рассмотрим ядерную часть ассоциативного поля Дархан (полужирным шрифтом выделено слово-стимул, курсивом - слова-реакции; в скобках указана частотность реакции).

Самая репрезентативная группа «Реалии» (буряты $1-22,5$ \%, буряты 2 $64,5 \%$, русские - $56 \%$ ) - здесь собраны реакции, которые связаны со стимулом и составляют элементы пропозиции [10. С. 220]. В этой семантической зоне располагаются самые частотные реакции бурят 2 и русских - молот (б2 26, p 25), подкова (б2 22, р 24). Кузнец работает с железом (б2 14, р 22) / түмэр (б1 12), сталью (б2 3, р 1), наковальней (б2 3, р 5), огнем (б2 2, р 3), изготавливает оружие (б2 1, р 2), меч (62 5, р 3), украмения (б2 б) / зҮҮдхэлнүҮд (б1 1). Кузнец - это ремесло (б2, р 2), специальность (б2, р 1), профессия (р 1). Буряты 2 и русские респонденты вспоминают поговорку «Каждый человек кузнец своего счастья» (62 14, р 9). 


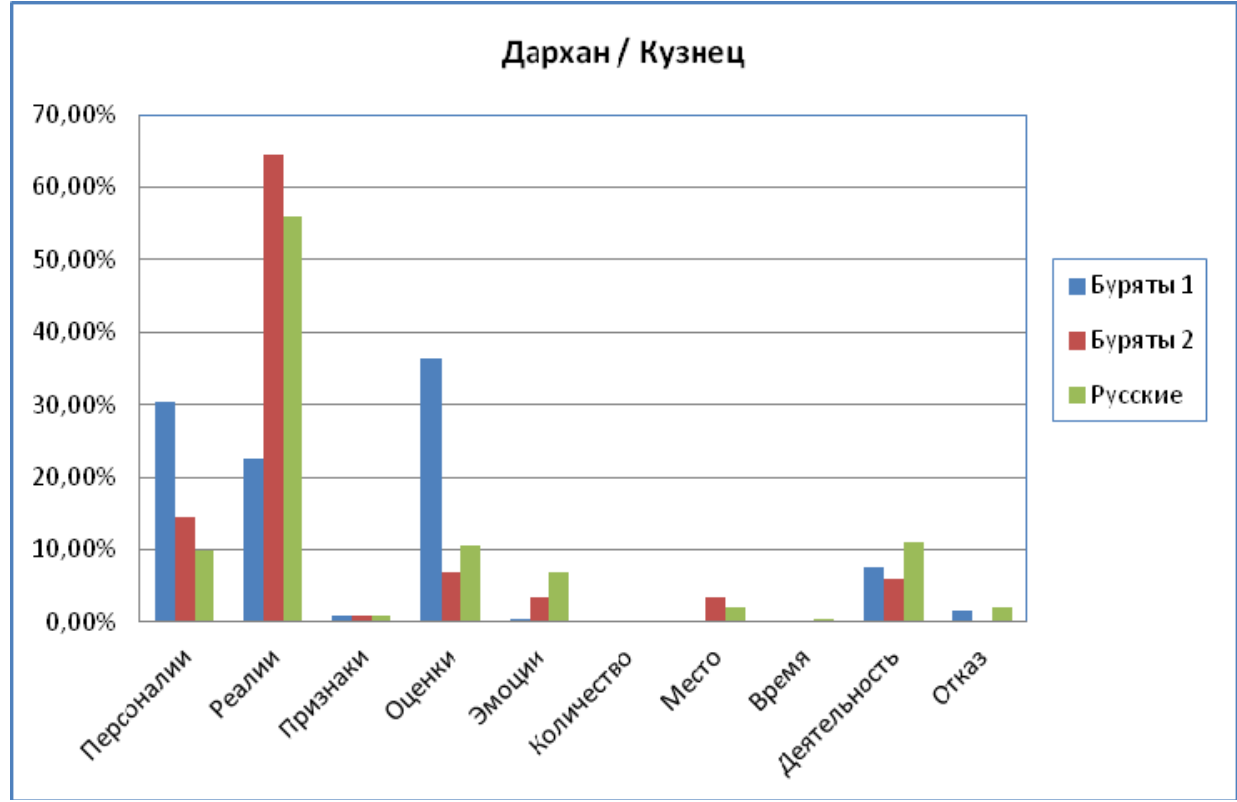

Рис. 1

У бурят 1 дархан работает с алтан 'золотом' (4), модон 'деревом' (9), занимается барилга 'строительством' (1) - даиан 'даиан, ламаисткий храм' (2), гэр 'дом', шэнэ гэр 'новый дом' (1), бригада, Үүдэн 'дверь, ворота', стол, хадааһан 'гвоздь' (1), харуул 'рубанок', шулуун 'камень' (1). Буряты 2 назвали следующие ассоциации: клещи, олово, песня «КИШ», трава, фильм «Пираты Карибского моря» (1), тяжесть, кувалда, мельница, седло, топор (1). У русских респондентов выявлены реакции: изделие, искусство (1), копыто, ножниць (1). В связи с кузнецом были названы следующие животные: лошадь (б2, р 1), корова (б2 1).

В ядерной части ассоциативного поля Дархан находится и семантическая зона «Персоналии»: буряты - 30,5\%, буряты $2-14,5 \%$, русские $-10 \%$. В этой группе присутствует тип связи номинация. Для всех групп респондентов кузнец - ремесленник (б2 2), работник (б2 6, р 3), рабочий (б2 3, p 2)/ хүдэлмэришэн (б1 1), ажалшан (б1 2), для бурят 1 дархан - это хүн 'человек' (16), для бурят 2 (6) и русских (3) - мастер.

Русские респонденты говорят о кузнеце Вакуле (1) (персонаж повести Н.В. Гоголя «Ночь перед Рождеством»), Гефесте (2) (бог огня в греческой мифологии), Вуттоне (1) (персонаж произведения Д. Толкиена «Кузнец из большого Вуттона»). Кузнец - богатырь (1), мужик (2), здоровый мужик (1). Буряты 2 называют имена Вася, Фома (1), кузнец - это он, мечник (1), видимо, изготовляет мечи.

Для бурят 1 дархан - это эрэ 'мужчина' (5), баабай (4), аба (2) 'отеи', Убгэн 'старик; муж' (3), таабай 'дед, дедушка', абга 'брат отиа, родной дядя (по линии отиа)', хүбүҮн 'сын; мальчик; парень' (1). Кузнечное ремесло в бурятской культуре обычно передавалось по наследству. Дархан занимает- 
ся не только металлом, но и деревом - барилгаша 'строитель', модошон 'плотник' (3), столяр (2), гэр баряаша 'строитель дома' (1), зураашан 'художник' (1).

Интересны реакции у бурят 1 и 2 дархан - бөө (5) / шаман (2), бурхан ‘божество' (1), эти реакции свидетельствуют о культе кузнеца в бурятской культуре. Этот культ связан с еще более архаичным культом огня, игравшим важную роль в верованиях и обрядах древних монголов [10. С. 76]. Почитание кузнеца в процессе эволюции культа прошло через три этапа: а) кузнец почитаемый как божество, демиург; б) кузнец - медиатор, посредник между своими божествами-покровителями и людьми; в) кузнец - изгой, относимый обществом к низшему сословию, к «нечистым». В языковом сознании современных бурят, как мы видим, отразились первые два этапа, кузнец как божество и как посредник, т.е. шаман.

Семантическая зона «Оценки» также располагается в ядерной части ассоциативного поля Дархан: буряты $1-36,5 \%$, буряты $2-7 \%$, русские 10,5 \%. Здесь присутствуют реакции, которые указывают коннотацию. Большой процент реакций в этой семантической зоне у бурят 1, для них дархан уран 'искусный' (32), бэрхэ 'опьттный, умелый, искусный' (11), алтан гартай 'с золотыми руками' (6), гартаа уран 'с умельми руками' (5). Общая ассоциация у респондентов - сильный (б2 3, р 4) / шадалтай (б1 (10), хүшэтэй (б1 2), кузнец - силач (р 1), у него есть сила (б2 3, р 5). Буряты 2 и русские дают положительную оценку - работяга, трудяга, молодец (1). Для бурят кузнец бэлигтэй 'разумный, мудрый; даровитый, одаренный, талантливый' (1).

Рассмотрим периферийную часть ассоциативного поля Дархан.

Семантическая зона «Деятельность»: буряты $1-7,5 \%$, буряты $2-6 \%$, русские - $11 \%$. Все респонденты дали ассоциации работа (p, б2 б), труд (б2 6, р 5) / ажал (б1 2). Кузнец занимается ковкой (б2 2, р 1), кует (б2 1, р 10), должен ковать (б2 2, р 4). Для бурят 1 дархан дархална 'мастерит что-л.' (6), сохино 'бьет' (2), табиба 'поставил' (1), должен зураха 'рисовать' (1), абаха 'брать' (1).

Семантическая зона «Эмоции»: буряты $1-0,5 \%$, буряты $2-3,5 \%$, русские $-7 \%$. У респондентов в связи с кузнецом возникает ассоциация счастье (б2 7, р 13), эта реакция талаан 'счастье, удача' у бурят 1 единична. С образом кузнеца в русской свадебной символике связаны представления о крепком и прочном браке, который он должен сковать для жениха и невесты, как сковывают железо [11. С. 297]. Кузнец является постоянным персонажем любовных (приворотных) заговоров. Русские также упомянули месть (1).

Семантическая зона «Место» (тип связи - локация): буряты 2 - 3,5\%, русские - 2 \%. Кузнец работает в кузнице (б2 7, р 3) или в поле (р 1). Кузница, находившаяся чаще всего на окраине русского селения, играла роль «мужского клуба»: возле нее собирались мужики, не только наточить плуг или подковать коня, но и обсудить местные новости, а то и выяснить отношения [11. С. 295].

Семантическая зона «Признаки» относится к периферийной части ассоциативного поля Дархан: буряты $1-1 \%$, буряты $2-1 \%$, русские $-1 \%$. Для этой зоны характерна предикация в узком смысле - описание признака предмета. Для бурят 2 и русских кузнец - старый, железныц̆, красный (1), у бу- 
рят 1 выявлена реакция хара 'черный', что связано с культом дархана в бурятской культуре. Кузнецы делились на «черных» и «белых», как и шаманы [10. С. 78]. Это, по-видимому, связано с цветовой символикой народов Центральной Азии, в которой белый цвет считался сакральным, священным, а черный содержит негативную оценку и является символом зла, несчастья. (1).

Семантическая зона «Время» имеется только у русских $(0,5 \%)-$ давно

Общее число реакций, \%

\begin{tabular}{l|c|c|c}
\hline \multicolumn{1}{c|}{ КУЗНЕЦ } & Буряты 1 & Буряты 2 & Русские \\
\hline Персоналии & 30,5 & 14,5 & 10 \\
\hline Реалии & 22,5 & 64,5 & 56 \\
\hline Признаки & 1 & 1 & 1 \\
\hline Оценки & 36,5 & 7 & 10,5 \\
\hline Эмоции & 0,5 & 3,5 & 7 \\
\hline Количество & - & - & - \\
\hline Место & - & 3,5 & 2 \\
\hline Время & - & - & 0,5 \\
\hline Деятельность & 7,5 & 6 & 11 \\
\hline Отказ & 1,5 & - & 2 \\
\hline
\end{tabular}

Рассмотрим значение дархан, данное в бурятско-русском словаре C.M. Бабушкина: 1. кузнец, мастер, умелый, искусный мастер; 2. искусный, умелый; алташа дархан золотых дел мастер, ювелир; бууша дархан ружейник; модошо (или модоной) дархан плотник; мүнгэшэ дархан мастер по серебру; түмэршэ дархан кузнец, слесарь [5. С. 85-86].

В словаре Л.Д. Шагдарова, К.М. Черемисова, который на сегодняшний день является наиболее полным изданием, дается подробная словарная статья [6. С. 261]. Дархан (түмэршэ дархан, модошо дархан) - это 1) кузнец, мастер, умелец, искусный мастер; гар дархан ремесленник; алташа дархан золотых дел мастер, ювелир; бууша дархан оружейник; модошо (или модоной) дархан плотник; модошо дархаар хүдэлмэрихэ; нарин дархан столяркраснодеревщик; мүнгэнииэ дархан мастер по серебру, серебряник; түмэриэ дархан кузнец; түмэрэй дархан кузнец; түмэршэ, модошо дархад кузнецы и плотники; һилбэридээ бэрхэ дарханууд чеканщики; ханын дархан мастер по изготовлению решеток для юрт; эмэлээй дархан мастер по изготовлению сёдел; һилуүршэ дархан резчик по дереву; булагша дархан мастер росписи по дереву; сагади ба хара дарханууд «белые» и «черные» кузнецы; 2) дархан саган тэнгэри шаманский бог кузнечного ремесла (покровитель рода «белых» кузнецов, имелись покровители и «черных» кузнецов); дархан удха генеалогия шамана-кузнеца; 3) (мн. дархад) ист. дархан вольный, лично свободный (не связанный повинностями).

Сравним лексикографическое и психолингвистическое значения слова дархан. Первое значение - общее, отраженное в словарях, - это ремесленник, мастер, работник, занимающийся ковкой, работающий в кузнище с наковальней, имеющий инструменты - молот, молоток, представлено в свободном ассоциативном эксперименте у бурят 1 и бурят 2. Дархан занимается железом, металлом, изготавливает оружие, мечи, подковы. У бурят 2 (64,5 \%) (как 
и у русских респондентов 56 \%) наиболее полно отражена семантическая зона «Реалии», для сравнения у бурят $1-22,5 \%$.

Отличительным является тот факт, что в языковом сознании бурят 1 , как и в лексикографических словарях, дархан является еще плотником, столяром, строителем, обрабатывает не только железо и металл, но и камень, дерево рубанком, строит дома, делает двери, сёдла, такие реакции отсутствуют у бурят 2. Для бурят 1 дархан работает с золотом как ювелир, художник, возможно, и как мастер росписи по дереву, у бурят 2 имеется реакция украшение (6). В бурятском языковом сознании (буряты 1,2$)$ отсутствует лексикографическое значение чеканщик, мастер по серебру, резчик по дереву. Как мы видим, первое словарное значение слова дархан присутствует в языковом сознании бурят 1 и бурят 2 , но с сужением области занятий.

Буряты 1 (36,5 \%) уделяют большое внимание «оценке» дархана, первая по наполняемости семантическая зона, для сравнения буряты $2-7 \%$, русские $-10,5 \%$. Как и в словарных статьях, кузнец - умелый (самая частотная реакция у бурят 1 (32), искусный мастер с золотыли руками.

Второе словарное значение дархан саган тэнгэри «шаманский бог кузнечного ремесла» было выявлено в ходе ассоциативного эксперимента как у бурят 1 , так и у бурят 2 . Но это значение находится на периферии ассоциативного поля, респонденты дали ассоциации, связанные с данным понятием: буряты 1 - 'бөө' шаман (5), 'даиан' буддийский храм (2), бурхан 'боге, божестве' (1), 'хара' черный (1), буряты 2 - шаман (1). Согласно представлениям шаманистов, древней религии бурят, помимо мира людей существуют другие миры, населенные духами. Шаманы выступают как посредники между миром людей и миром духов [12. С. 28-29]. Белые шаманы почитали духов предков рода, в то время как черные совершали моления духам шаманских предков. Черные шаманы обозначались как хара бөө, что указывало на их сильную магическую силу. Разные миры взаимосвязаны и взаимопроницаемы, поэтому духи могут влиять на жизнь, здоровье и благополучие людей. Функция шаманов заключалась в возвращении, установлении гармонии в природе между мирами. И белые и черные шаманы занимались налаживанием нарушенных отношений, и те и другие умели предсказывать. В XVII в. среди бурятшаманистов распространяется буддийское течение ламаизм, который ассимилирует шаманские представления, культы и обряды, в том числе связанные с дарханом. Это объясняет наличие таких реакций в эксперименте.

Третье значение слова дархан «вольный, лично свободный (не связанный повинностями)», которое зафиксировано в бурятско-русском словаре, на сегодняшний день отсутствует в языковом сознании бурят. Хотя в истории культуры бурят и монголов это значение существовало в качестве этнонима рода-племени, соционима страты «свободных», сословия «вольных от податей» членов общества [13. С 9.].

\section{Выводы}

1. Свободный ассоциативный эксперимент дает возможность выявить реально функционирующее психолингвистическое значение слова в национальной культуре. 
2. Психолингвистическое значение слова не всегда шире, чем лексикографическое, зафиксированное в толковых словарях. В нашем случае значение слова «дархан» в бурятской культуре сужается. Сейчас в языковом сознании бурят 1 и 2 функционирует первое словарное значение слова дархан кузнеи, ремесленник, мастер, работаюший с металлом, оружием, а также $c$ золотом. У бурят 1 зафиксировано значение плотник, столяр, строитель, обрабатывающий камень и дерево. Но чеканщик, мастер по серебру, резчик по дереву не выявлено ни у одной из групп. Что касается второго значения, связанного с шаманизмом, дархан саган тэнгэри 'шаманский бог кузнечного ремесла', оно присутствует в языковом сознании бурят 1 и 2 на периферии ассоциативного поля, что говорит о сохранившихся религиозных воззрениях бурят. Для бурят 1 очень важна оценка дархана, они относятся к нему с большим уважением, а буряты 2 называют предметы, связанные с кузнецом. Это подтверждает то, что кузнечный культ в бурятской культуре, включающий в себя почитание горна, меха, наковальни, кузнечных инструментов, оборудования и самого кузнеца, получивший широкое распространение среди монгольских народов с древнейших времен, сохранился до нашего времени. Третье значение дархан вольный, лично свободный (не связанный повинностями) не выявлено.

3. Образ дархана в языковом сознании бурят 1 и бурят 2 имеет общие черты, но всё же образ кузнеца в языковом сознании бурят 2 , не владеющих бурятским языком, говорящих только на русском, имеет гораздо больше сходств с образом кузнеца в русской культуре, чем с образом дархана бурят 1. Это связано со снижением функционирования бурятского языка, который, к сожалению, уступает русскому как языку повседневного общения и для многих этнических бурят является единственным родным языком.

\section{Лumepamypa}

1. Тарасов Е.Ф. Межкультурное общение - новая онтология анализа языкового сознания // Этнокультурная специфика языкового сознания / отв. ред. Н.В. Уфимцева. М., 2003. С. 7-22.

2. Белянин В.П. Психолингвистика. М.: Флинта: Московский психолого-социальный институт, 2005. 232.

3. Тарасов Е.Ф., Тарасова М.Е. Исследование ассоциативных полей представителей разных культур // Ментальность россиян / под общ. ред. И.О. Дубова. М., 1997. С. 253-277.

4. Жалсанова Ж.Б. Этническая составляющая гендерного стереотипа в языковом сознании русских и бурят: дис. ... канд. филол. наук. М., 2009. Прил. 1. Ассоциативные словари. С. 189212.

5. Бабушкин C.M. Бурятско-русский и русско-бурятский словарь. Улан-Удэ: Изд-во ОАО «Республиканская типография», 2004. 566 с.

6. Шагдаров Л.Д., Черемисов К.М. Бурятско-русский словарь. Улан-Удэ: Изд-во ОАО «Республиканская типография», 2006. Т. 1. 635 с.

7. Стернин И.А., Рудакова А.В. Проблемы создания психолингвистического толкового словаря русского языка // Вопр. психолингвистики. 2012. С. 174-183.

8. Дырхеева Г.А. Бурятско-русское двуязычие: социальная стратификация (к проблеме изучения) // Вестн. Бурят. гос. ун-та. 2012. Спецвыпуск С. С. 190-193.

9. Караулов Ю.Н. Ассоциативная грамматика русского языка. 2-е изд. М.: ЛКИ, 2010. $332 \mathrm{c}$.

10. Абаева Л.Л. Ареальная характеристика кузнечного культа в традиционной обрядности бурят // Культурно-бытовые традиции бурят и монголов. Улан-Удэ, 1988. С. 76-102.

11. Мужики и бабы: Мужское и женское в русской традиционной культуре: иллюстр. энцикл. / Д.Б. Баранов, О.Г. Баранова, Т.А. Зимина и др. СПб.: Искусство-СПБ, 2005. 688 с. 
12. Галданова Г.Р. Бурятский шаманизм: прошлое и настоящее // Сибирь: этносы и культуры. Улан-Удэ, 1998. С. 5-46.

13. Дашиева Н.Б. Кузнечный культ бурят: историко-культурные истоки // Вестн. Вост.Сиб. гос. акад. культуры и искусств. 2013. № 1 (4). С. 7-19.

THE CONCEPT "DARKHAN / SMITH" IN THE BURYAT CULTURE (THE PSYCHOLINGUISTIC MEANING)

Vestnik Tomskogo gosudarstvennogo universiteta. Filologiya - Tomsk State University Journal of Philology. 2017. 45. 89-99. DOI: 10.17223/19986645/45/6

Zhargalma B. Zhalsanova, National Research University Higher School of Economics (Moscow, Russian Federation). E-mail: komma2001@yandex.ru

Keywords: ethnopsycholinguistics, language consciousness, associative experiment, psycholinguistic meaning, lexicography word meaning, concept darkhan / smith.

The article is devoted to the analysis of the associative field "darkhan / smith" in the language consciousness of the Buryat people. Data for the analysis are the results of an associative experiment, one of research methods of language consciousness, which gives a possibility to reveal the systemacity of the content of an image of consciousness behind the word in culture, its ethnocultural specifics. With the leading role of the Russian language as a language for communication in the Republic of Buryatia, it was interesting to find out the common and specific features in the image "darkhan" in the language consciousness of the bilingual Buryat people and of the Buryats with Russian as a native language. The associative reactions classification "semantic Gestalt" by Yu.N. Karaulov is used for the analysis; it reflects the internal semantic organization of the associative field and characterizes the field as a complete unit of knowledge of the world.

The article deals with the analysis of the lexicographic meanings of the word "darkhan" [smith]. Data of the Buryat-Russian dictionaries by S.M. Babushkin, L.D. Shagdarov and K.M. Cheremisov are attracted for the analysis; these are the most unabridged editions nowadays. In this work the functioning of the dictionary meanings of the word "darkhan" in the language consciousness of the bilingual Buryat people and the Buryats with native Russian is described.

The psycholinguistic and lexicographic meanings of the word "darkhan" are considered in the article. The psycholinguistic word meaning (term of I.A Sternin and A.V. Rudakova) is understood as an ordered unity of all semantic components which staticizes a separate word in the consciousness of native speakers; it is a word meaning actually functioning in the language consciousness of native speakers. The result of the analysis has shown that the psycholinguistic word meaning is not always broader than lexicographic, recorded in explanatory dictionaries, as I.A. Sternin and A.V. Rudakova state. The meaning of the word "darkhan" in the Buryat culture is narrowed. One of the reasons of this process is the weak position of the Buryat language as the daily main language of communication in the Republic of Buryatia. At present, the first dictionary meaning of the word "darkhan", "a smith, a handicraftsman, a craftsman working with metal, weapon and also with gold", functions in the language consciousness of the Buryat. The bilingual Buryat people have the meaning "a carpenter, a joiner, a builder working with stone and wood". But the word meaning "a chiseller, a craftsman working with silver, a woodcarver" is not identified in any of the groups.

\section{References}

1. Tarasov, E.F. (2003) Mezhkul'turnoe obshchenie - novaya ontologiya analiza yazykovogo soznaniya [Intercultural communication: a new ontology analysis of linguistic consciousness]. In: Ufimtseva, N.V. (ed.) Etnokul'turnaya spetsifika yazykovogo soznaniya [Ethnocultural specificity of language consciousness]. Moscow: Institute of Linguistics, RAS.

2. Belyanin, V.P. (2005) Psikholingvistika [Psycholinguistics]. Moscow: Flinta: Moscow Psychological and Social Institute.

3. Tarasov, E.F. \& Tarasova, M.E. (1997) Issledovanie assotsiativnykh poley predstaviteley raznykh kul'tur [Associative field study in different cultures]. In: Dubov, I.O. (ed.) Mental'nost' rossiyan [Mentality of Russians]. Moscow: Imidzh-kontakt. 
4. Zhalsanova, Zh.B. (2009) Etnicheskaya sostavlyayushchaya gendernogo stereotipa v yazykovom soznanii russkikh $i$ buryat [Ethnic component of gender stereotype in language consciousness of the Russians and the Buryats]. Philology Cand. Diss. Moscow.

5. Babushkin, S.M. (2004) Buryatsko-russkiy i russko-buryatskiy slovar' [The Buryat-Russian and Russian-Buryat dictionary]. Ulan-Ude: Respublikanskaya tipografiya.

6. Shagdarov, L.D. \& Cheremisov, K.M. (2006) Buryatsko-russkiy slovar' [The Buryat-Russian dictionary]. Vol. 1. Ulan-Ude: Respublikanskaya tipografiya.

7. Sternin, I.A. \& Rudakova, A.V. (2012) Problemy sozdaniya psikholingvisticheskogo tolkovogo slovarya russkogo yazyka [Problems of creating a psycholinguistic explanatory dictionary of the Russian language]. Voprosy psikholingvistiki - Issues of Psycholinguistics. 16. pp. 174-183.

8. Dyrkheeva, G.A. (2012) Buryat-Russian bilingualism: social stratification (to the problem of study). Vestnik Buryatskogo gosudarstvennogo universiteta - BSU Bulletin. Special Issue C. pp. 190193. (In Russian).

9. Karaulov, Yu.N. (2010) Assotsiativnaya grammatika russkogo yazyka [Associative Russian grammar]. 2nd ed. Moscow: LKI.

10. Abaeva, L.L. (1988) Areal'naya kharakteristika kuznechnogo kul'ta v traditsionnoy obryadnosti buryat [Areal characteristics of the smith cult in the traditional rites of the Buryats]. In:Basaeva, K.D. \& Nimaev, D.D. (eds) Kul'turno-bytovye traditsii buryat i mongolov [Cultural and community traditions of Buryatia and Mongolia]. Ulan-Ude: BB SB USSR AS.

11. Baranov, D.B. et al. (2005) Muzhiki i baby: Muzhskoe i zhenskoe v russkoy traditsionnoy kul'ture. Illyustr. Entsiklopediya [Men and women: Men and women in the Russian traditional culture. Illustrated encyclopedia]. St. Petersburg: Iskusstvo-SPB.

12. Galdanova, G.R. (1998) Buryatskiy shamanizm: proshloe i nastoyashchee [Buryat shamanism: Past and Present]. In: Sokolova, Z.S. et al. (eds) Sibir': etnosy i kul'tury [Siberia: ethnic groups and cultures]. Ulan-Ude: East-Siberian State Academy of Culture and Arts.

13. Dashieva, N.B. (2013) The blacksmith's cult of Buryats: historical and cultural roots. Vestnik Vostochno-Sibirskoy gosudarstvennoy akademii kul'tury i iskusstv. 1(4). pp. 7-19. (In Russian). 